Published by the International Journal of Project Management

doi: 10.1016/j.ijproman.2016.10.012

\title{
Addressing Individual Perceptions: An Application of the Unified Theory of Acceptance and Use of Technology to Building Information Modelling
}

\author{
Robert Howard ${ }^{1}$ \\ Luis Restrepo ${ }^{2}$ \\ Chen-Yu Chang ${ }^{3}$
}

\begin{abstract}
Building Information Modelling (BIM) is a technology with the potential to transform the construction industry, yet its proliferation remains stagnant. Existing research on BIM diffusion focuses on the industry, company, and project levels while disregarding the impact of perceptions at the individual level. This research aims to extend the Unified Theory of Acceptance and Use Technology (UTAUT) model to understand the perceptions that individuals have towards working with BIM. A survey was completed by 84 industry stakeholders and the results analysed against a modified UTAUT model that adds the variable of Attitude and employs moderators of Experience and Voluntariness. The results reveal that Performance Expectancy does not directly affect Behavioural Intention, signifying that BIM is perceived as an unrewarded addition to existing work processes. These findings evince the need to redefine strategies, policies, and incentive schemes in order to advance the acceptance of BIM in the U.K. and worldwide.
\end{abstract}

Keywords: building information modelling (BIM), unified theory of acceptance and use of technology (UTAUT), diffusion of innovations, construction, technology adoption

\footnotetext{
1 Bartlett School of Construction and Project Management, University College London, Torrington Place, London WC1E 7HB; PH (44) 20-76791266; email: robert.howard.09@ucl.ac.uk (corresponding author)

2 Bartlett School of Construction and Project Management, University College London, Torrington Place, London WC1E 7HB; PH (44) 20-76791266; email: luis.restrepo.13@alumni.ucl.ac.uk

3 Bartlett School of Construction and Project Management, University College London, Torrington Place, London WC1E 7HB; PH (44) 20-76791266; email: chen-yu.chang@ucl.ac.uk
} 


\begin{tabular}{ll} 
Abbreviations and Acronyms \\
AECO & Architecture, Engineering, Construction, and Operations \\
AT & Attitude \\
BI & Behavioural Intention \\
BIM & Building Information Modelling \\
CFA & Confirmatory Factor Analysis \\
CFI & Comparative Fit Index \\
EE & Effort Expectancy \\
ERP & Enterprise Resource Planning \\
FC & Facilitating Conditions \\
GFI & Goodness of Fit Index \\
IDT & Innovation Diffusion Theory \\
IS & Information System \\
PE & Performance Expectancy \\
RMSEA & Root Mean Square of Error Approximation \\
SEM & Structural Equation Modelling \\
SI & Social Influence \\
TAM & Technology Acceptance Model \\
TPB & Theory of Planned Behaviour \\
TRA & Theory of Reasoned Action \\
UB & User Behaviour \\
UTAUT & Unified Theory of Acceptance and Use of Technology \\
\hline
\end{tabular}




\subsection{Introduction}

In recent years, Building information modelling (BIM) has been promoted as the ultimate solution for the coordination problems that plague construction supply chains. Yet despite a great deal of attention within academia and industry, BIM's diffusion remains slow. In a definition provided by the National Institute of Building Sciences (2007), a BIM model:

...utilizes cutting edge digital technology to establish a computable representation of all the physical and functional characteristics of a facility and its related project/lifecycle information, and is intended to be a repository of information for the facility owner/operator to use and maintain throughout the life-cycle of a facility.

The critical items within this definition are BIM's role as a central repository for information, and that it covers the entire lifecycle of a facility, meaning from its earliest conception up through its demolition. In this role, a BIM model allows the structure to be built virtually, thereby detecting clashes and informing upon optimal sequencing in a way that is simply not possible using paper-based representations. Where BIM truly shines, however, is in its augmentation of the three dimensional space with the additional dimensions of cost, time and facilities management.

With such incredible benefits, it is widely recognized that BIM has the potential to transform the AECO industry. As a result, the U.K. Government has developed a strategy to promote the adoption of BIM within industry by seeking to achieve the implementation of fully collaborative BIM in all public sector projects by 2016 (BIM Task Group, 2013). Despite this charge, the diffusion of BIM across the AECO industry has been protracted. According to a survey of 70 major U.K. construction organisations by law firm Pinsent Masons, the majority of respondents (64\%) predict that the U.K. government's goal is not 
achievable. This result begs the questions as to what factors are impeding the adoption of BIM within industry.

The deferred adoption has certainly not gone unnoticed by academia. That said, the focus of current research has focused solely on the aggregate (industry, company or project) level. In such studies, several impediments to BIM adoption have been identified, including: low awareness, lack of training, fragmentation of the industry, difficulties in changing traditional work processes, nebulous roles and responsibilities in deploying BIM within organizations, and software interoperability issues. From the perspective of technology diffusion, there is one type of inhibitor that has not been investigated: the perception of BIM by users. A survey of 375 organisations indicated that individual user resistance is the topranked challenge for the implementation of large-scale information technologies (ITtoolbox, 2004). Since BIM is at its heart an information technology, it would stand to reason that it be impacted by the same forces; namely, the perceptions of individuals. The research problem thus becomes how BIM is perceived by individual users and how those perceptions influence BIM's application on a project.

It is recognized that people who do not fully accept an innovation could delay, hinder, underutilize or even disrupt its implementation (Brown, et al. 2002). Since acceptance is an individual act based on personal perceptions, philosophically the current research is guided by the need to identify what perceptions influence behaviour (ie. acceptance) so that the aggregate benefits of project-level acceptance can be realized. In short, this research contends that users' perceptions towards collaborative BIM plays a pivotal role in its current low rate of adoption.

The significance of this factor for the case of BIM adoption remains an empirical issue, in response to which this research aims to provide an apposite empirical analysis. The 
empirical model is based on the unified theory of acceptance and use of technology (UTAUT) developed by Venkatesh et al. (2003). Built upon the highly influential TAM model (Davis, 1989), Venkatesh et al. (2003) refines, integrates, and validates the constructs of eight previous technology acceptance methodologies into a single model, making UTAUT a robust basis for exploring a wide range of technology diffusion issues (Wu, et al. 2007; Keong, et al. 2012; Oh \& Yoon 2014). Seven hypotheses were derived through the modification of UTAUT and tested through a survey employing structural equation modelling (SEM).

The findings of this study should be of special interest to policymakers, companies, and organizations interested in the diffusion of BIM with important insights on policies, incentives, work strategies, and role structuring potentially stemming from the research. The study also investigates the UTAUT model and its robustness for predicting the diffusion of BIM, enhancing academic research on technology and innovation acceptance.

\subsection{Literature review}

\subsection{Prior Studies on BIM Adoption}

Given the potential impact of BIM on the AECO industry, the topic of BIM adoption has spawned a vast amount of literature, but as noted previously the focus is overwhelmingly on the industry, project, and company levels. For example, Bercerik-Gerber and Rice (2010) utilized surveys to test the perceived value of BIM in the USA's building industry at the project level while Bryde et al. (2013) focused on the project level to address the benefits of BIM from a project management perspective.

Some recent research identified the barriers to successful BIM adoption taken from case study reviews of BIM-enabled projects. Conversely, others employed surveys to present 
the same issue. Panuwatwanich and Peansupap (2013) applied Everett Rodgers' innovation diffusion theory (IDT) to study factors affecting the diffusion of BIM at the project level. Among others, Azhar (2011) used online surveys to identify common barriers to BIM implementation throughout the U.S. construction industry and Gu and London (2010) applied information from the Australian construction industry to study the technical and nontechnical issues that require consideration in implementing BIM.

It has been noted that overcoming barriers to BIM has a direct connection with the performance of individuals in their jobs, which goes to the core of the research question. For example, learning curves in training and education can be optimized if employees learn more quickly, as changes in work processes can be imposed with greater ease, less cost, etc. (Fishbein \& Ajzen 1975; Kleinbeck 1987). As proven by a large body of empirical research documented in the literature of organizational psychology, Kleinbeck (1987, p. 261) explains that "motivation influences goal directed action and is an essential characteristic of jobperformance." Therefore, it is important to discover whether individuals in the AECO industry perceive that using BIM will in fact translate into benefits for themselves as practitioners.

While it may seem as if the benefits and factors identified within literature also apply to the individual level, this is not the case. For instance, classifying productivity as an individual level benefit can prove problematic because achieving the same work in less time may result in fewer paid hours. This same dilemma exists with many other aggregate level benefits, meaning that the individual level may be inversely affected by benefits at the project or company levels. Existing literature does not yet address the personal benefits of BIM for practitioners at the individual level; a research gap this study aims to fill. 


\subsection{Technology Acceptance for Information Systems and UTAUT}

The acceptance of information technology has been heavily studied by management information system (MIS) researchers. Coinciding with the rise of personal computers in the 1980s, issues associated with the acceptance of this emergent technology began receiving research attention. Influenced by the theory of reasoned action (Fishbein and Ajzen, 1975), Davis et al. (1989) suggests that two beliefs are essential for one's Attitude towards the usage of computers: perceived usefulness (to what extent a person believes using a computer could enhance his or her job performance) and perceived ease of use (to what extent a person believes using a computer could be free of effort). Attitudes shape one's Behavioural Intention to use a technology, which would necessarily in turn affect actual system usage. Davis (1989) demonstrates these two beliefs to be empirically valid measures.

The model created by Venkatesh et al. (2003) has been utilized in the study of many types of technology acceptance, ranging from Chen et al. (2011) who tested the applicability of the UTAUT model in playing online games through mobile phones to Tong et al. (2011) which explained the intention to use an enterprise resource planning system by using the UTAUT model. Yet despite wide ranging UTAUT research and considerable academic attention towards BIM, no existing studies have applied the UTAUT model to BIM proliferation.

The theories used to create UTAUT draw upon the theory of reasoned action (TRA), the technology acceptance model (TAM), the motivational model (MM), the theory of planned behaviour (TPB), the combined TAM-TPB model, the model of PC utilization (MPCU), the IDT and the social cognitive theory (SCT). In constructing the UTAUT model, Venkatesh et al. (2003) tested all of these constructs and combined them to form a set of new and refined factors that affect Behavioural Intention and User Behaviour of an information 
system. Specifically, UTAUT predicts that the Behavioural Intention of an information system is affected by the following factors:

1. Performance Expectancy: The extent to which users of the system believe it will help them achieve gains in job performance.

2. Effort Expectancy: The extent to which the use of the system is easy for the individual.

3. Social Influence: The extent to which individuals perceive that important people believe they should use the system.

Similarly, the model predicts that the User Behaviour of an information system is impacted by:

1. Behavioural Intention: This construction is made up of Performance Expectancy, Effort Expectancy, and Social Influence.

2. Facilitating Conditions: This construct refers to the extent to which an individual believes the organization is there to support the use of the system.

In addition, the model identifies four moderators which, in theory, affect the relationships between these constructs. The moderators are: age, gender, voluntariness of use, and experience. Figure 1 illustrates the original UTAUT model.

Figure 1: UTAUT Model (Venkatesh, et al., 2003)

\subsection{Limitations of UTAUT and the Incorporation of Attitude}

A limitation of the model is that it is primarily based upon theories constructed for voluntary environments (such as the Technology Acceptance Model) where users can decide upon usage of the system (Keong, et al. 2012, p. 174). However, the decision of adoption and 
usage of BIM across the AECO industry is often decided at an organizational or project level, making the use of BIM mandatory for the individual level. As a result, some theoretical considerations of mandatory use of systems must be taken into account for the application of UTAUT to individuals.

Under mandatory settings, employees must use the system to perform their job functions and thus intention does not affect the actual User Behaviour of the system (Koh, et al. 2010, p. 177). This is the reason why the construct of Behavioural Intention becomes less important. Actually, research under strict mandatory settings evinces that Behavioural Intention may not be an appropriate dependent variable in the model (Brown, et al. 2002, p. 283). Whilst introducing the moderator of voluntariness into the UTAUT model might mitigate this problem (Venkatesh et al. (2003, p. 455)), research suggests that not including Attitude as a key construct causes an imprecise depiction of the actual User Behaviour (Brown, et al. 2002). By definition, Attitude refers to "an individual's positive or negative feelings about performing the target behaviour" (Fishbein \& Ajzen 1975, p. 216). There exists a strong body of literature arguing that when an organization mandates use, Attitude (and not the Behavioural Intention) should be used as a key construct (Keong, et al. 2012, p. 177). For example, Keong at al. (2012) finds that employee resistance appears to be the second most important contributor to time and budget over-runs and the fourth most important barrier to implementation. The key insight is that under mandatory settings, usage will represent the level necessary to perform the minimal required tasks, and that any usage beyond this point is voluntary. As a result, models of mandatory use of systems (BIM being a case) should include Attitude as a key construct (Brown et al., 2002; Yousafzai et al., 2007;

Koh et al. 2010). 


\subsection{Research Methodology}

This research commenced with a comprehensive literature review revealing that the UTAUT model provides a powerful and flexible theoretical framework for probing the perception of BIM at the individual level. Some issues with the model were addressed in order to suit the research purpose. Specifically, the UTAUT model was adapted to reflect the limitations and suggestions made by literature. First, Attitude was included as an independent variable affecting User Behaviour. Second, moderators were adjusted in order to tailor the model to the context of BIM and the scope of the research itself with the removal of age and gender. Age was removed because the moderator of experience addresses this construct with respect to BIM use. Given the fact that BIM is a specialized information technology and not in general use, and also taking into account the sample size of the research, the moderator of gender was not seen to fit with the model and was therefore removed. All of these constructs were validated using an interview approach. The proposed model for the study is shown in Figure 2:

Figure 2: Proposed framework for UTAUT model as applied to BIM

\subsection{Approach}

Within UTAUT and TAM literature, a Likert-scale survey is normally employed for collating data in respect of the perceptions of IT system users which is then examined statistically through the use of structural equation modelling (SEM). As such, a closed ended, seven point Likert-scale survey was chosen with 1 meaning strongly disagree and 7 strongly agree and the data subsequently analysed using an econometric model (a copy of the full questionnaire is provided at the conclusion of the narrative). The primary analysis methodology of crosssectional data econometric analysis is expounded upon below, as is the data collection strategy. 


\subsection{Variables and Hypotheses}

Overall the hypotheses were drafted to correspond with the path relationships theorized by the established UTAUT model. Figure 2 illustrates that the model contains nine variables in total: two dependent variables, five independent variables, and two moderating variables. The first dependent variable, Behavioural Intention, refers to the intention of the person to use the technology, and the model predicts that Performance Expectancy, Effort Expectancy, and Social influence could all affect this variable. Based on this composition, the following hypotheses were developed:

- Hypothesis 1: Performance Expectancy can strengthen individuals' Behavioural Intention to use BIM.

- Hypothesis 2: Effort Expectancy has a positive effect on individuals' Behavioural Intention to use BIM.

- Hypothesis 3: Social Influence will exert a positive influence on the individual's Behavioural Intention to use BIM.

The second dependent variable, User Behaviour, measures the actual involvement of the individual with BIM. As such, the model predicts that this variable could be influenced by three factors: Attitude, Facilitating Conditions, and Behavioural Intention. Hence, the following hypotheses are developed:

- Hypothesis 4: Attitude has a positive effect on one individual's usage of BIM.

- Hypothesis 5: Facilitating Conditions have a positive correlation with one individual's usage of BIM.

- Hypothesis 6: Behavioural Intention can increase one individuals' usage of BIM. 
Last, the model also predicts the effect of Attitude on individuals' Behavioural Intention to use BIM:

- Hypothesis 7 (H7): Attitude will have an influence with the individual's Behavioural Intention.

It should be noted that with Hypothesis 7 theoretical prediction does not align with the data that SEM provides. The model predicts that Attitude will influence User Behaviour but not Behavioural Intention. However, in the interest of uniformity for hypotheses direction (null vs. alternative/test), Hypothesis 7 is phrased as written. If theory holds, the level of significance for Attitude's influence on Behavioural Intention will be less than 95\% (i.e., insignificant).

\subsection{Moderating Variables}

The model is moderated by two variables in order to achieve robust conclusions. The variable of Voluntariness moderates the relationships according to the degree of freedom individuals had in choosing whether to utilize BIM. Additionally, the variable Experience measures how much practice the individual had in working with BIM. The respondent has four choices for this variable: none, less than two years, two to five years, and more than five years.

\subsection{Questionnaire Design}

The next step in the methodology was to design a questionnaire that tests the adapted UTAUT variant while using the original UTAUT model construct as a foundation for the decision-making context. Each variable is measured within the survey by a set of questions that, when combined, provide an accurate measure of that variable. The wording and format for the questions were based largely upon the seminal UTAUT questionnaire distributed by 
Venkatesh et al. (2003), providing inbuilt validity to the approach without the need for a pilot study.

After the questions were drafted, but prior to the full implementation of survey, interviews were held with two leading BIM experts. Both had extensive experience in the AECO industry and over seven years of experience with BIM. One is a BIM leader within an engineering consultancy firm and the other a senior project manager from a construction management firm. The purposes of the interviews were twofold: first, examine the clarity and appropriateness of wording and the answerability of questions; second, ensure that the questions are understood by the respondent as intended. Throughout the interviews, the constructs for all questions were validated within the context of BIM and individual technology acceptance. The inclusion of Attitude was one of the central topics, with the interviewees ultimately validating Attitude as an appropriate construct for BIM through the following comments:

1. Personally, I think that Attitude plays a big role in how individuals learn and use BIM. However, the Attitude is formed differently in each individual depending on a wide range of circumstances. I think it is a good idea to include it in the model. I think that measuring independently Attitude is not a problem for the model because you are just measuring a different variable and if it proves not to directly affect User Behaviour then all the other results from the original model still work. In conclusion, yes, I think you should include Attitude.

2. The feelings that employees have about working with BIM can be very important because we want them to be as motivated as possible and we know 
that having a good motivation will result in better job performance. In this sense, yes I think that the variable should be included in the model.

In the survey, respondents were first asked to provide some basic information about their experience with BIM and the subsector of the industry in which they work. Respondents were then asked to rate the extent to which they agreed with a set of statements within each category according to a seven-point Likert scale.

\subsection{Questionnaire Administration}

The questionnaire was conducted online with 364 professionals from various sectors of the AECO industry invited to participate. Of these 364, a total of 84 completed the survey for a response rate of 23 percent. The aim was to conduct the survey at the individual level, which is why the survey targeted not only senior BIM users but also more general participants within the U.K.'s AECO industry. The criteria for selecting these individuals were as follows:

- Employees of companies in the AECO industry.

- Excluding general management and sales employees.

- U.K. - based organizations only.

Any surveys that were incomplete were discarded and recorded as if there were no response at all.

\subsection{Analysis of Data Using SEM}

As noted previously, UTAUT traditionally utilizes SEM for statistical analysis. Accordingly, after the data from the surveys was collected SEM was employed for data analysis utilizing the AMOS II program. Aside from its established use within UTAUT research, SEM was also chosen due to its capacity to use latent variables with the maximum likelihood method 
applied to run the model. It was further determined to utilize Covariance-based SEM (CBSEM) over Partial Least Square SEM (PLS-SEM). This choice was based on Hair et al. 2011 who note that "If the research objective is theory testing and confirmation, then the appropriate method is CB-SEM. In contrast, if the research objective is prediction and theory development, then the appropriate method is PLS-SEM.” In this instance the questionnaire was designed to confirm that the data fits the UTAUT model, so CB-SEM was the optimal choice. If the goal had rather been to predict outcomes using the model, then PLS-SEM would have been employed.

Figure 3 illustrates the complete model constructed using SEM. The squared box variables are observed variables and represent the questions asked in the survey. The circled variables represent the latent or unobserved variables. Likewise, the circled variables labelled with "e" represent the error term of each construct. Lastly, the arrows indicate the path relationships between the different variables. SEM shows the unreliability of the measurement in the model, which theoretically leads to an accurate estimation of the relationships between latent variables.

Figure 3: Structural model using SEM (see Abbreviations and Acronyms on page 3)

\subsection{Data analysis and results}

\subsection{Goodness of Fit}

The optimal model specification is discovered through confirmatory factor analysis (CFA). In the process, constructs are dropped from the model if these constructs add no predictive 
power. The new model is then re-estimated and compared to the old model until no improvement can be made.

The acceptance of the optimal model is judged by the Chi-squared to degrees of freedom $\left(\mathrm{X}^{2} / \mathrm{DF}\right)$. A rule of thumb is that $\mathrm{X}^{2} / \mathrm{DF}<3$ for accepting the general specification of the model (Kline, 2011). In term of this index (2.659), the model can be deemed satisfactory. Another index, the Comparative Fit Index (CFI), measures the degree of incremental improvement when comparing the fit of two models (Bentler, 1990; Bentler and Bonett, 1980). CFI is a good measure for an exploratory study where the causal relationships between variables are ill-understood and the number of samples is small (Rigdon, 1996). The current research is of this nature. The question of interest is: Compared to the baseline model in which no paths are estimated, whether the model presented in Figure 3 is a better model. A concern of SEM is that goodness of fit can be easily achieved if the parsimony issue (i.e., including unnecessary variables to improve goodness of fit) is ignored (Iacobucci, 2010). As a result, an adjustment should be made. The adjustment formula for CFI by Mulaik et al. (1989) provides a good measure. The model of this research has the value of 0.774 in the adjusted CFI, which is over the threshold value of 0.75 (Rigdon, 1996), and thus can be accepted as a good fit. Tables 1 and 2 below summarize the values of the model fit measures:

Table 1: Chi-squared to degrees of freedom ratio

Table 2: Model fit measures

\subsection{Path Analysis}

In the previous section, CFA was performed to assess the model's GFI and loading of the research constructs. In this section, a path analysis for the structural model was conducted to examine the hypothesized relationships that assist in predicting individuals' Behavioural Intention and actual User Behaviour towards BIM. Figure 4 illustrates the structural model 
with the results of the assessed path coefficient and the adjusted coefficient of determination (R2) scores:

Figure 4: Path results for structural model (see Abbreviations and Acronyms on page 3)

In order to cross-validate the predictive validity of the regression and direct the model, one question related to each latent variable was assigned a weight of one (Pace 2014). As a result, the statistical significance of the questions used in the survey is fit to measure the latent variables.

\subsection{Results for Variables Theorized to Affect Behavioural Intention}

As shown in Table 3, the first hypothesis reveals that the path from Performance Expectancy to Behavioural Intention exhibits an exceedingly weak relationship in terms of coefficient (0.015) and p-value (0.921), meaning that Performance Expectancy does not significantly affect Behavioural Intention to use BIM. The hypothesis was thus rejected. This result appears at odds with what has been found in other applications of UTAUT, begging the question as to what particular characteristics make BIM unique amongst information systems.

The second hypothesis indicates that Effort Expectancy has a direct effect on individuals' Behavioural Intentions to use BIM, which is consistent with theory. The hypothesis was accepted based on the statistical indication that there is a strong effect $(0.407)$

of Effort Expectancy on Behavioural Intention with a low p-value less than the threshold value of 0.05 . This effect on the individual's Behavioural Intention to use BIM implies that potential and actual users value how easy it is to work with the technology.

The third hypothesis indicates that there is a significant relationship between Social Influence and the individual's Behavioural Intention to use BIM. In fact, the statistical result reveals that Social Influence has the greatest influence on Behavioural Intention (0.70) with 
the estimate remaining within the 95 percent confidence interval. Hence, Hypothesis 3 was accepted. This finding suggests that of all the variables affecting Behavioural Intention, the general opinion held by BIM users has the strongest influence on individuals' Behavioural Intentions towards BIM. In addition, the relationship between Social Influence and Behavioural Intention is moderated by voluntariness, in accordance with theory, where this relationship is strengthened, especially under mandatory settings (Brown, et al. 2002; Venkatesh, et al. 2003; Koh, et al. 2010).

\subsection{Results for Variables Theorized to affect User Behaviour}

Attitude is found to significantly affect User Behaviour. This additional construct, which Venkatesh et al. (2003) theorize to be covered by Performance Expectancy and Effort Expectancy proves to work differently in the case of BIM. In accordance with Brown et al. (2002), Yousafzai et al. (2007) and Koh et al. (2010), in which Attitude is predicted to be a separate construct affecting User Behaviour and considerably so within mandatory environments, Hypothesis 4 is accepted with a positive coefficient of 0.127 and a p-value just outside the 90 percent confidence interval. As a result, the positive or negative feelings about working with BIM led to an effect on User Behaviour.

On the other hand, Hypothesis 5 indicated that Facilitating Conditions has a significant effect on User Behaviour. This hypothesis was accepted since the statistical result reveals a strong relationship (0.543) which is consistent with theory.

Hypothesis 6 indicated that Behavioural Intention has a substantial relationship with User Behaviour, which was accepted since the estimate accounted for 0.218 and was within the confidence interval. In accordance with theory, the model predicts that Behavioural Intention affects the actual User Behaviour of individuals with regards to BIM. 
Finally, Hypothesis 7 (H7) stated that Attitude would influence Behavioural Intention. The results showed a negative path coefficient and a very high $\mathrm{P}$ value (0.444), which evidences a weak statistical significance for this relationship. In the rejection of this hypothesis the theoretical prediction of the model is confirmed.

\section{Table 3: Model Outcomes}

The results predict four important correlations between variables (shown in Table 5):

\section{Table 4: Correlations}

Performance Expectancy has significant correlations with Facilitating Conditions of 0.284 , with Attitude of 0.648 , and with Social Influence of 0.306. These correlations demonstrate that the Performance Expectancy in individuals has profound effects within the model. The correlation with Social Influence is explained as the more that individuals perceive that important people think they should use BIM, the higher expectancy they will have regarding their job performance if they do work with BIM. Under this reasoning, increasing Social Influence correlates to higher expectancy in the job, and vice versa. Effort Expectancy and Facilitating Conditions likewise possess a significant correlation of 0.609 , which explains how the conditions given to individuals affects the effort they expect to put into working with BIM, and vice versa.

As a result, this study reveals that five of the seven proposed hypotheses are accepted and statistically significant. A summary of the results for the hypotheses is shown in Table 5, and the revised model based on the SEM results shown in Figure 5.

Table 5: Hypothesis testing results

Figure 5: Revised Model Based on SEM Results 


\subsection{Discussion}

The results of this study have several implications. In the model, four independent variables (Social Influence, Effort Expectancy, Attitude, and Facilitating Conditions) are proven to have a significant effect on the Behavioural Intention and actual User Behaviour in working with BIM. By contrast, Performance Expectancy had a low effect on Behavioural Intention, which is contrary to existing theory and the hypothesis. Accordingly, the moderator of experience proved to have a strong effect on the relationship between Performance Expectancy and Behavioural Intention.

\subsection{AT as a New Construct}

The new variable incorporated in the model, Attitude (AT), had a significant effect on User Behaviour. Thus, the proposed variation increased the model's predictability by adding a further construct that affects User Behaviour. This suggests that compared to the original UTAUT model, the proposed variation provides a better fit to explain BIM acceptance at the individual level. Since a high proportion of the individuals use BIM under mandatory environments, the variable of Attitude did imply a significant effect on User Behaviour and not on Behavioural Intention. This finding matches previous research performed on the mandatory use of technology (Brown, et al. 2002; Yousafzai, et al. 2007; Koh, et al. 2010). On the other hand, it contrasts with the findings of Venkatesh et al. (2003), which theorized that Attitude affects Behavioural Intention and is covered by the variables of Performance Expectancy and Effort Expectancy. However, the correlation found between Attitude and Performance Expectancy does suggest that these variables are related. As such, this research contends that Attitude should be included as a separate variable within the context of BIM acceptance. 
As stated in the literature review, Performance Expectancy is composed of measures of perceived usefulness, extrinsic motivation, job-fit, relative advantage, and outcome expectations. These measures are theorized by existing literature to affect Behavioural Intention, but the low effect of Performance Expectancy towards Behavioural Intention suggests that perhaps individuals do not regard BIM as an instrument to enhance their performance at work. This is the most significant departure from existing theory and indicates that there may be other forces influencing how individuals perceive BIM's impact on job performance. It would appear that BIM is perceived more as a hurdle to completing tasks or as a required additional imposition that does not affect their overall job performance. In short, working with BIM is seen as an additional unrewarded task for individuals and innovations such as BIM are not creating Performance Expectancy at the individual level - perceptions which may impede the diffusion of BIM. This crucial implication requires further research within each sector and role within AECO in order to take into account the industry's high fragmentation.

The strong moderating effect that experience has on relationships underlines the perception that working with BIM does not create expectancy at the individual level. As experience accumulates with the concept of BIM, individuals would (in theory) expect this knowledge to be rewarded by either increased in salary or increased job performance. On the contrary, what is actually occurring is that the more experience one has with BIM, the less the Performance Expectancy. As a result, working with BIM evolves into a routine task for individuals rather than representing a performance-enhancing tool. BIM enthusiasts should focus on developing strategies to link BIM usage to individual job performance to overcome this perception. 


\subsection{Other Relationships and Correlations}

It is noted that other variables in the model also play a crucial role. First, the results of the model illustrate that experience has a significant effect on voluntariness. Specifically, the more experience one has with BIM the less mandatory their decision is to use BIM. As people accumulate experience and progress in their careers, they are placed in decisionmaking positions and can eventually choose whether or not to use BIM.

Second, Social Influence has the strongest influence on Behavioural Intention. Thus far, positive communication and effective transmission of influential people's positive opinions of BIM are the strongest contributors to individuals' intentions towards BIM. Efforts to increase Behavioural Intention may include efficient communication and improved interaction of influential people in the industry regarding the use of BIM.

Third, Effort Expectancy and Facilitating Conditions are two closely related variables that influence the diffusion of BIM. There is a strong correlation between the two, and although one affects Behavioural Intention and the other User Behaviour, the more effort individuals perceive they have to exert in order to use BIM the poorer they regard the work tools for the system, and vice versa. This implies that the better the work tools (including training, software, hardware, etc.), the easier it will be for individuals to work with BIM, and thus the more intention and subsequent use there will be. Also, the more user-friendly BIM becomes, the better the perception of the Facilitating Conditions.

Finally, Performance Expectancy's correlation with Attitude, Social Influence, and Facilitating Conditions evinces the need for understanding how improving one of these constructs will lead to an improvement in the correlated variables.

\subsection{Policy Implications}


This study provides a path for BIM enthusiasts to improve the acceptance of BIM in the U.K.'s AECO industry. Understanding the influence of the measured variables on individual acceptance of BIM advocates for a reconsideration of current strategies for BIM incentivization, while the lack of Performance Expectancy suggests that the benefits generated by using BIM are not reaching individuals working within the industry. Benefits appear at the industry, company, or project level while leaving individuals remain unrewarded.

A revision of the current policies could consider channelling part of these benefits towards the individual level. Incentives, raises, promotions, etc., may have a positive impact on accelerating the acceptance of BIM if they can be adequately integrated into current policy. This shift in expectancy may help the industry redefine work processes and create a collaborative environment more rapidly.

As mentioned previously, the U.K. Government is a vocal supporter of establishing BIM in the AECO industry. However, their strategy of requiring the use of BIM for public projects is focused primarily at the company level, leaving the individuals' involvement subject to each firm's interpretation. This policy could be refined in order to incentivize the individual level. For example, a scheme in which employee certifications in BIM add points to the overall score of a company's bid for a Government project. This could feasibly create Performance Expectancy in practitioners as companies reward employees for progressing their skills in BIM in order to make their firm more competitive in public bids. Consequently, this should improve collaboration within the fragmented AECO industry as it would be in individuals' best interest to accept BIM. 
The results of this research suggest that there exists the potential to accelerate the diffusion of BIM by complementing current policies to develop Performance Expectancy in the industry's practitioners.

\subsection{Conclusion}

This research aims to explore the issues that have impeded the proliferation of BIM through the survey of perception of individuals in the U.K.'s AECO industry towards working with BIM. The data is analysed using the UTAUT model, a highly influential and robust approach for understanding technology acceptance of information systems. Behavioural Intention and User Behaviour were selected to measure the involvement of individuals with BIM based on an extensive literature review. In terms of independent variables, Performance Expectancy, Effort Expectancy, Attitude, Facilitating Conditions, and Social Influence were undertaken. Among them, Attitude was an addition to the original UTAUT model. The model also included two moderating variables: experience and voluntariness.

The data covers the perceptions of 84 professionals from within industry. The proposed model therefore successfully passed the Chi-squared to degrees of freedom, demonstrating a reasonable model fit for the data. The observed results indicate that Performance Expectancy is not impacting Behavioural Intention, contrary to what is proposed within literature. Furthermore, individuals may not expect job performance gains from working with BIM, a perception which seems to be moderated by experience: The more experience accumulated in BIM, the less Performance Expectancy perceived. In addition, Attitude proved to positively influence User Behaviour, confirming the modification of the original UTAUT model for the concept of BIM. Finally, the model also revealed a series of correlations between Performance Expectancy and Attitude, Performance Expectancy and Social Influence, Performance Expectancy and Facilitating Conditions, and between Effort 
Expectancy and Facilitating Conditions, which help to explain how these variables affect the diffusion of BIM and their interrelation.

From an academic standpoint, three main contributions are made to literature: first, the focus area of the individual level as few BIM-related previous studies have investigated this perspective. Second, that individual perceptions can be linked to the diffusion of BIM, particularly with regards to the lack of influence Performance Expectancy has upon Behavioural Intention. Third, the final model is a validated modification of the original UTAUT model which contributes to the research of technology acceptance.

With regards to industry impact, it is important to note that Social Influence, defined as the extent to which individuals perceive that important people believe they should use the system, has the greatest influence on employees' Behavioural Intention and that Facilitating Conditions, or the extent to which an individual believes the organization is there to support the use of the system, has the greatest impact on User Behaviour. This is a key understanding for practitioners because unlike variables such as Attitude and Experience, company and project management can largely control these two constructs. This means that firms seeking to implement BIM can effectively shape employees perceptions and use of the technology by emphasizing that leadership believes in the system and then providing excellent support during implementation.

Another key takeaway for practitioners is that Performance Expectancy, or the extent to which users of the system believe it will help them achieve gains in job performance, did not significantly impact Behavioural Intention with BIM. This was the most significant departure from theory and indicates that at least in the case of BIM, the technology is largely perceived as an unrewarded addition to existing work processes that is not creating Performance Expectancy at the individual level. It is therefore incumbent upon firms to 
thoroughly educate employees on how BIM will improve their job performance and career advancement. Without doing so, they run the risk of not achieving full buy-in from the team and thus put the effectiveness of the overall implementation in jeopardy.

\subsection{Limitations of this Research and Recommendations for Further Study}

It is conceded that the study possesses some limitations. First, it did not examine other important possible moderators such as sector, salary level, and career expectations; moderators which could account for much of the fragmentation within the industry. Second, perceptions and Behavioural Intention were measured from the point of view of the respondents. This may have an impact in the generalizability of the results as individuals' personal characteristics and experience could allow for a unique understanding of the questions. Third, due to the sample size, the fit measures for the model used in SEM are not optimal. Nonetheless, they still provide sufficient validity and reliability to reach the conclusions stated.

When analysed from a general approach, the results provide avenues through which to extend research on the topic: Behavioural Intention varied according to the level of experience, indicating a need for a better understanding of the effects that BIM characteristics have on the feelings of users towards innovation. As a result, previous studies on information technology acceptance illustrate certain difficulties in explaining new technologies such as BIM. The great variety of technologies, their evolving nature and increasing complexity suggest that previous theories on technology acceptance may need to evolve accordingly.

In particular, this research suggests that it is important to accommodate the fragmented characteristics of the AECO industry in future models, which in turn may benefit from utilizing this tailored version. For example, the various levels of involvement between stakeholders in a project may produce divergent outcomes in the BI and UB towards BIM. 
These general implications support previous suggestions made by Venkatesh et al. (2003) and Venkatesh and Morris (2000), who suggest that Technology Acceptance Models should be modified to some extent depending upon the particular characteristics of the information system under in study. Nonetheless, the model in this case provides an appropriate insight of BIM acceptance within the construction industry. The outcomes of the relationships between the variables evidence in general terms how individuals in the industry are currently accepting the concept of BIM.

At the industry, company, and project levels, BIM is a technological innovation that provides extraordinary benefits when used properly. However, this research suggests that at the individual level, the additional work resulting from BIM, the fragmented nature of construction, and current work processes ultimately reduce BIM to merely a change in workflow procedures. 


\subsection{References}

Alshawi, M. and Ingirige, B. (2003). "Web-enabled project management: An emerging paradigm in construction." Automation in Construction, July, 12(4), 349-364.

Alwadhi, S. and Morris, A. (2008). "The use of the UTAUT Model in the adoption of egovernment services in Kuwait." Proceedings of the 41st Annual Hawaii International Conference on System Sciences, 1(1), 219.

Ashworth, A. (2012). "The impact of building information modeling: transforming construction." Construction Management and Economics, 30(2), 183-185.

Azhar, S. (2011). "Building information modeling (BIM): Trends, benefits, risks, and challenges for the AEC industry." Leadership and Management in Engineering, July, 11(3), 241-252.

Barlish, K. and Sullivan, K. (2012). "How to measure the benefits of BIM - A case study approach." Automation in Construction, July, 24, 149-159.

Barrett, P. (2007). "Structural equation modelling: Adjudging model fit." Personality and Individual Differences, 42(5), 815-824.

Becerik-Gerber, B. and Rice, S. (2010). "The perceived value of building information modeling in the U.S. building industry." Journal of Information Technology in Construction, February, 15, 185-201.

Bernstein, H. M. et al. (2014). The business value of BIM for construction in major global markets: How contractors around the world are driving innovation with building information modelling. McGraw Hill Construction.

Bentler, P.M., 1990. Comparative fit indexes in structural models. Psychological bulletin, $107,238$.

Bentler, P.M., Bonett, D.G., 1980. Significance tests and goodness of fit in the analysis of covariance structures. Psychological bulletin, 88, 588.

BIM Task Group (2013). BIM Task Group, $<$ http://www.bimtaskgroup.org/about> (Aug. 10, 2014).

Brown, S., Massey, A., Montoya-Weiss, M. and Burkman, J. (2002). "Do I really have to? User acceptance of mandated technology." European Journal of Information Systems, December, 11(4), 283-295.

Bryde, D., Broquetas, M. and Volm, J. M. (2013). "The project benefits of building information modelling (BIM).” International Journal of Project Management, 31, 971-980.

Casey, T. and Wilson-Evered, E. (2012). "Predicting uptake of technology innovations in online family dispute resolution services: An application and extension of the UTAUT." Computers in Human Behavior, 28(6), 2034-2045. 
Chen, L. S.-L., Kuan, C. J., Lee, Y.-H. and Huang, H.-L. (2011). “Applicability of the UTAUT model in playing online game through mobile phones: Moderating effects of user experience." First International Technology Management Conference, 1(1), 625-629.

Davis, F.D., 1989. Perceived usefulness, perceived ease of use, and user acceptance of information technology. MIS quarterly, 13, 319-340.

Davis, F.D., Bagozzi, R.P., Warshaw, P.R., 1989. User acceptance of computer technology: a comparison of two theoretical models. Management science, 35, 982-1003.

Dossick, C. S., Neff, G. and Homayouni, H. (2009). The Realities of Building Information Modeling for Collaboration in the AEC Industry. s.1., s.n., 396-405.

Eastman, C., Teicholz, P., Sacks, R. and Liston, K. (2011). BIM handbook - A guide to building information modeling for owners, managers, designers, engineers, and contractors (2nd ed), Hoboken, NJ; John Wiley \& Sons, Inc.

Fang, W.-C., Li, M.-W. and Liu, C.-W. (2008). "Measurement of the knowledge-sharing efficacy of Web2.0 site constructed on the basis of knowledge-based systems by applying the model of UTAUT: Evidence of the early adopters." $20083 \mathrm{rd}$ International Conference on Innovative Computing Information and Control, 1(1), 372.

Fishbein, M. and Ajzen, I. (1975). Belief, Attitude, intention and behavior: An introduction to theory and research. Addison-Wesley, Reading, MA.

Grudz, A., Staves, K. and Wilk, A. (2012). "Connected scholars: Examining the role of social media in research practices of faculty using the UTAUT model." Computers in Human Behavior, 28(6), 2340-2350.

Gu, N. and London, K. (2010). "Understanding and facilitating BIM adoption in the AEC industry." Automation in Construction, December, 19(8), 988-999.

Hair, J.F., Ringle, C.M. and Sarstedt, M.(2011) PLS-SEM: Indeed a Silver Bullet. Journal of Marketing Theory and Practice, vol. 19, no. 2 (spring 2011), pp. 139-151.

Homayouni, H., Neff, G. and Dossick, C. S. (2010). Theoretical Categories of Successful Collaboration and BIM Implementation within the AEC Industry. s.1., s.n., 778788.

ITtoolbox, ERP implementation Survey, 2004. (Accessed in December 2015 at www.vvsgidas.lt/)

Iacobucci, D., 2010. Structural equations modeling: Fit indices, sample size, and advanced topics. Journal of Consumer Psychology, 20, 90-98.

Kaba, B. and Toure, B. (2014). "Understanding information and communication technology behavioral intention to use: Applying the UTAUT model to social networking site adoption by young people in a least developed country." Journal of the Association for Information Science and Technology, 65(8), 1662-1674. 
Kaner, I., Sacks, R., Kassian, W. and Quitt, T. (2008). "Case studies of BIM adoption for precast concrete design by mid-sized structural engineering firms." Journal of Information Technology in Construction, June, 13, 303-323.

Keong, M. L., Ramayah, T., Kurnia, S. and Chiun, L. M. (2012). "Explaining intention to use an enterprise resource planning (ERP) system: An extension of the UTAUT model.” Business Strategy Series, 13(4), 172-180.

Kim, Y. J., Chun, J. U. and Song, J. (2009). "Investigating the role of Attitude in technology acceptance from an Attitude strength perspective." International Journal of information Management, February, 29(1), 67-77.

Kleinbeck, U. (1987). "The effects of motivation on job performance." Motivation, Intention, and Volition, 261-271.

Kline, R.B., 2011. Principles and practice of structural equation modeling. Guilford press.

Koh, C. E., Prybutok, V. R., Ryan, S. D. and Wu, Y. (2010). "A model for mandatory use of software technologies: An integrative approach by applying multiple levels of abstraction of informing science." Informing Science: The International Journal of an Emerging Transdiscipline, 13, 177-203.

Lin, C.-P. and Anol, B. (2008). "Learning online social support: An investigation of network information technology based on UTAUT." Cyberpsychology \& behavior: The impact of the Internet, multimedia and virtual reality on behavior and society, 11(3), 268-272.

Mathieson, K. (1991). "Predicting user intentions: Comparing the technology acceptance model with the theory of planned beahvior." Information Systems Research, September, 2(3), 173-191.

Merschbrock, C. and Munkvold, B. E. (2014). Succeeding with Building Information Modeling: A Case Study of BIM Diffusion in a Healthcare Construction Project, Waikoloa, s.n., 3959-3968.

Min, Q., Ji, S. and Qu, G. (2008). "Mobile commerce user acceptance study in China: A revised UTAUT model.” Tsinghua Science \& Technology, 13(3), 257-264.

Mulaik, S.A., James, L.R., Van Alstine, J., Bennett, N., Lind, S., Stilwell, C.D., 1989. Evaluation of goodness-of-fit indices for structural equation models. Psychological bulletin, 105, 430 .

National Building Information Modeling Standard (NBIMS) (2007). National Building Information Modeling Standard Version 1.0.

Oh, J.-C. and Yoon, S.-J. (2014). "Predicting the use of online information services based on a modified UTAUT model." Behaviour \& Information Technology, 33(7), 716729.

Oliviera, T., Faria, M., Thomas, M. A. and Popovic, A. (2014). "Extending the understanding of mobile banking adoption: When UTAUT meets TTF and ITM." International Journal of Information Management, 34(5), 689-703. 
Pace, R. K. (2014). "Maximum likelihood estimation." The Handbook of Regional Science, M. M. Fischer and P. Nijkamp, eds., Baton Rouge: Springer Berlin Heidelberg, 1553-1569.

Rigdon, E.E., 1996. CFI versus RMSEA: A comparison of two fit indexes for structural equation modeling. Structural Equation Modeling: A Multidisciplinary Journal, 3, 369-379.

Savalei, V. and Bentler, P. M. (2010). "Structural equation modeling." The Corsini Encyclopedia of Psychology.

Smith, P. (2014). "BIM \& the 5D project cost manager." Procedia - Social and Behavioral Sciences, 119, 475-484.

Succar, B. (2009). "Building information modelling framework: A research and delivery foundation for industry stakeholders." Automation in Construction, 18, 357-375.

Szajna, B., 1996. Empirical evaluation of the revised technology acceptance model. Management science, 42, 85-92.

Tong, W. et al. (2011). "Examination of UTAUT model in an ERP postadoption environment: An empirical study." 2011 International Conference on E-Business and E-Government, 1(1), 1-4.

Venkatesh, V. and Morris, M. G. (2000). "Why don't men ever stop to ask for directions? Gender, Social Influence, and their role in technology acceptance and usage behavior.” MIS Quarterly, March, 24(1), 115-139.

Venkatesh, V., Morris, M. G., Davis, G. B. and Davis, F. D. (2003). "User acceptance of information technology: Toward a unified view." MIS Quarterly, September, $27(3), 425-478$.

Wills, M. J., El-Gayar, O. F. and Bennett, D. (2008). "Examining healthcare professionals' acceptance of electronic medical records Using UTAUT." Issues in Information Systems, 9(2), 396-401.

Wu, Y.-L., Tao, Y.-H. and Yang, P.-C. (2007). Using UTAUT to explore the behavior of $3 G$ mobile communication users. Singapore, s.n., 199-203.

Yousafzai, S. Y., Foxall, G. R. and Pallister, J. G. (2007). "Technology acceptance: a metaanalysis of the TAM: Part 2." Journal of Modelling in Management, 2(3), 281-304.

Zhou, T., Lu, Y. and Wang, B. (2010). "Integrating TTF and UTAUT to explain mobile banking user adoption." Computers in Human Behavior, 26(4), 760-767. 


\subsection{Questionnaire}

\begin{tabular}{|c|c|c|}
\hline \multicolumn{3}{|c|}{ Personal Information (optional) } \\
\hline \multicolumn{2}{|c|}{ Name: } & \\
\hline \multicolumn{2}{|c|}{ Organisation Name: } & \\
\hline \multicolumn{2}{|c|}{ Division/Business Unit: } & \\
\hline \multicolumn{2}{|c|}{ Email: } & \\
\hline \multicolumn{3}{|r|}{ Control Questions } \\
\hline \multirow{2}{*}{\multicolumn{2}{|c|}{ Sex }} & Male \\
\hline & & Female \\
\hline \multirow{5}{*}{\multicolumn{2}{|c|}{ Age }} & Under 25 \\
\hline & & $26-35$ \\
\hline & & $36-45$ \\
\hline & & $46-55$ \\
\hline & & Over 55 \\
\hline \multirow{10}{*}{\multicolumn{2}{|c|}{$\begin{array}{l}\text { In which area of the } \\
\text { construction industry is } \\
\text { your organisation } \\
\text { specialized? }\end{array}$}} & Construction/Engineering \\
\hline & & Consultancy (cost management, project management, etc.) \\
\hline & & Design/Architecture \\
\hline & & Property Development \\
\hline & & Operations (property management, facilities management, etc.) \\
\hline & & Manufacturing \\
\hline & & Logistics \\
\hline & & Legal \\
\hline & & Real Estate and Financial Institution \\
\hline & & Other (please specify) \\
\hline \multirow{5}{*}{\multicolumn{2}{|c|}{$\begin{array}{l}\text { How much experience } \\
\text { do you have with BIM } \\
\text { (years)? }\end{array}$}} & None \\
\hline & & Less than 2 \\
\hline & & 2 to 5 \\
\hline & & 6 to 10 \\
\hline & & More than 10 \\
\hline \multicolumn{3}{|r|}{ BIM Involvement } \\
\hline \multicolumn{3}{|c|}{ Please complete the following statement by selecting one of the following options: } \\
\hline 1 & \multicolumn{2}{|l|}{ Not at all } \\
\hline 2 & \multicolumn{2}{|l|}{ To a little extent } \\
\hline 3 & \multicolumn{2}{|l|}{ To some extent } \\
\hline 4 & \multicolumn{2}{|l|}{ Undecided } \\
\hline 5 & \multicolumn{2}{|c|}{ To a moderate extent } \\
\hline 6 & \multicolumn{2}{|l|}{ To a great extent } \\
\hline 7 & \multicolumn{2}{|c|}{ To a very great extent } \\
\hline VOL & \multicolumn{2}{|c|}{ The decision to get involved with BIM was voluntary? } \\
\hline $\mathrm{Bl} 1$ & \multicolumn{2}{|c|}{ I intend to work with BIM in the next 36 months... } \\
\hline $\mathrm{BI} 2$ & \multicolumn{2}{|c|}{ I predict I would use BIM in the next 36 months... } \\
\hline $\mathrm{BI3}$ & \multicolumn{2}{|c|}{ I plan to use BIM in the next 36 months... } \\
\hline UB1 & \multicolumn{2}{|c|}{ Involvement with BIM in my job... } \\
\hline UB2 & \multicolumn{2}{|c|}{ My organization's involvement with BIM... } \\
\hline
\end{tabular}




\begin{tabular}{|c|l|}
\hline \multicolumn{2}{|c|}{ BIM Perceptions } \\
\hline $\begin{array}{c}\text { Considering your personal opinion on BIM, please indicate your level of agreement with the following } \\
\text { statements: }\end{array}$ \\
\hline 1 & Strongly disagree \\
\hline 2 & Disagree \\
\hline 3 & Somewhat disagree \\
\hline 4 & Undecided \\
\hline 5 & Somewhat agree \\
\hline 6 & Agree \\
\hline 7 & Strongly agree \\
\hline PE1 & I would find BIM useful in my job. \\
\hline PE2 & Working with BIM enables me to accomplish tasks more quickly. \\
\hline PE3 & Working with BIM increases my productivity. \\
\hline PE4 & If I work with BIM, I will increase my chances of getting a raise. \\
\hline EE1 & My interaction with BIM would be clear and understandable. \\
\hline EE2 & It would be easy for me to become skilled at working with BIM. \\
\hline EE3 & I would find BIM easy to use. \\
\hline EE4 & Leaning to operate BIM is easy for me. \\
\hline AT1 & Using BIM is a good idea. \\
\hline AT2 & BIM makes work more interesting. \\
\hline AT3 & Working with BIM is fun. \\
\hline AT4 & I like working with BIM. \\
\hline SI1 & People who influence my behaviour think I should use BIM. \\
\hline SI2 & People who are important to me think that I should use BIM. \\
\hline SI3 & The senior management of this business has been helpful in the use of BIM. \\
\hline SI4 & In general, the organisation has supported the use of BIM. \\
\hline FC1 & I have the resources necessary to work with BIM. \\
\hline FC2 & I have the knowledge necessary to work with BIM. \\
\hline FC3 & BIM is not compatible with the work tools I use. \\
\hline FC4 & A specific person (or group) is available for assistance with BIM difficulties. \\
\hline
\end{tabular}




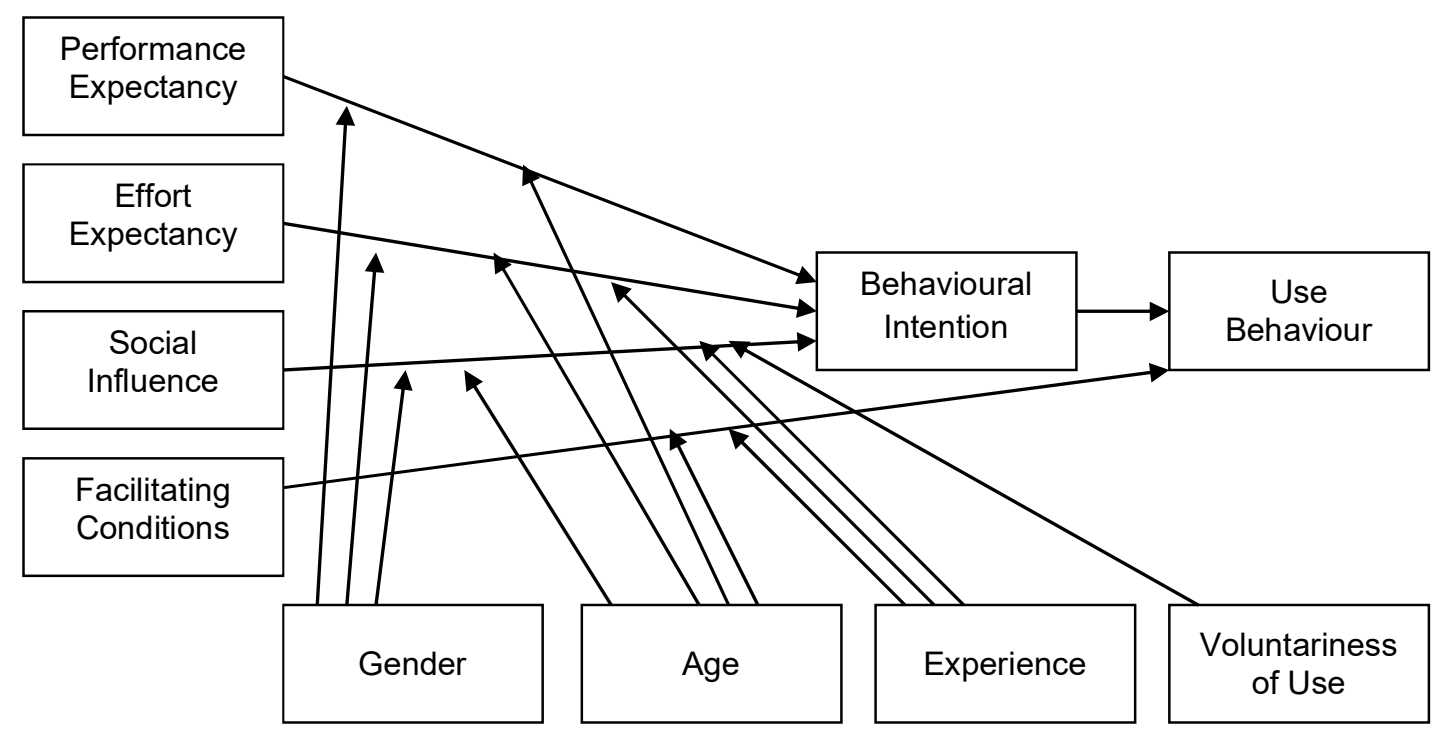

Figure 1: UTAUT Model (Venkatesh, et al., 2003) 


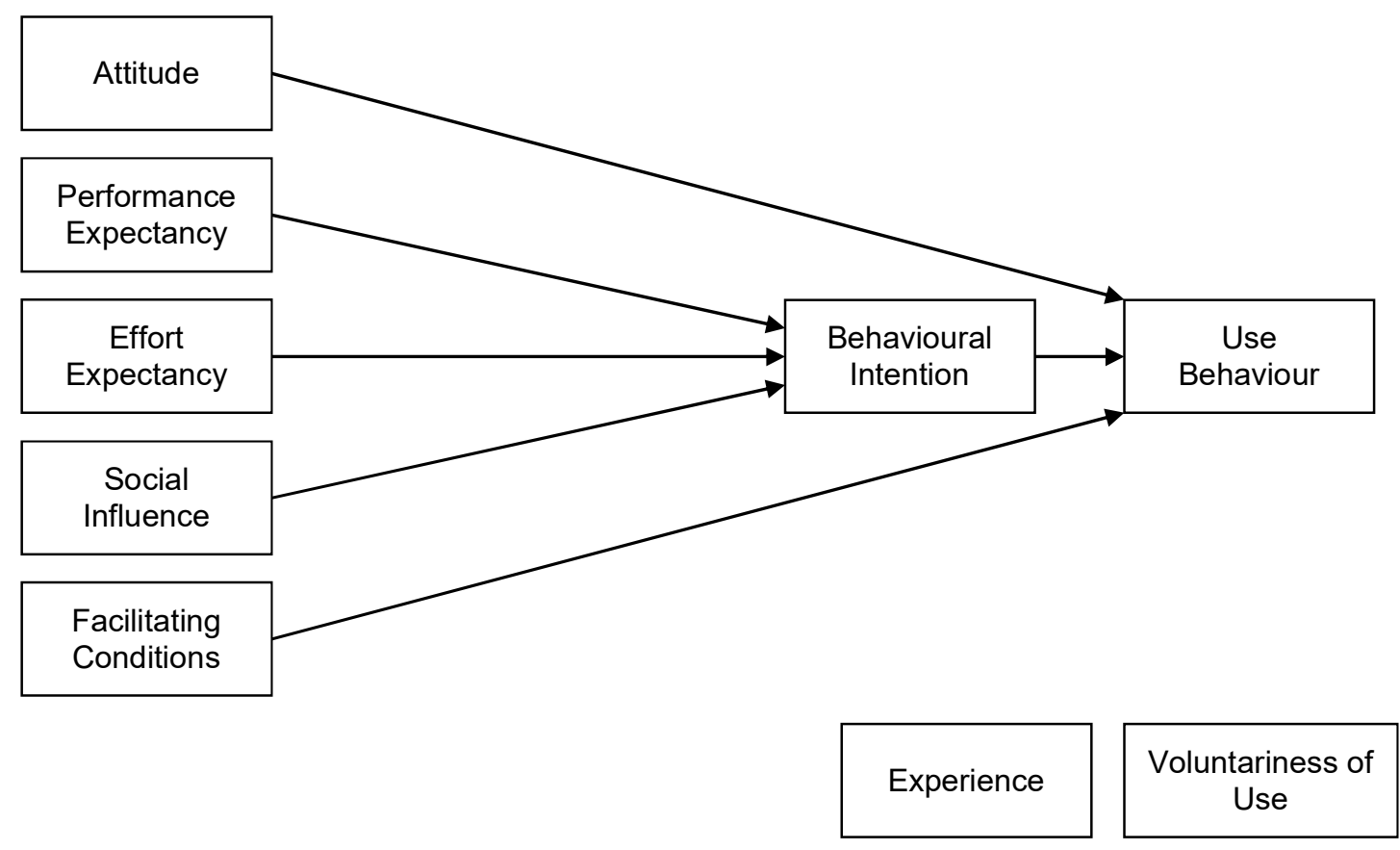

Figure 2: Proposed framework for UTAUT model as applied to BIM 


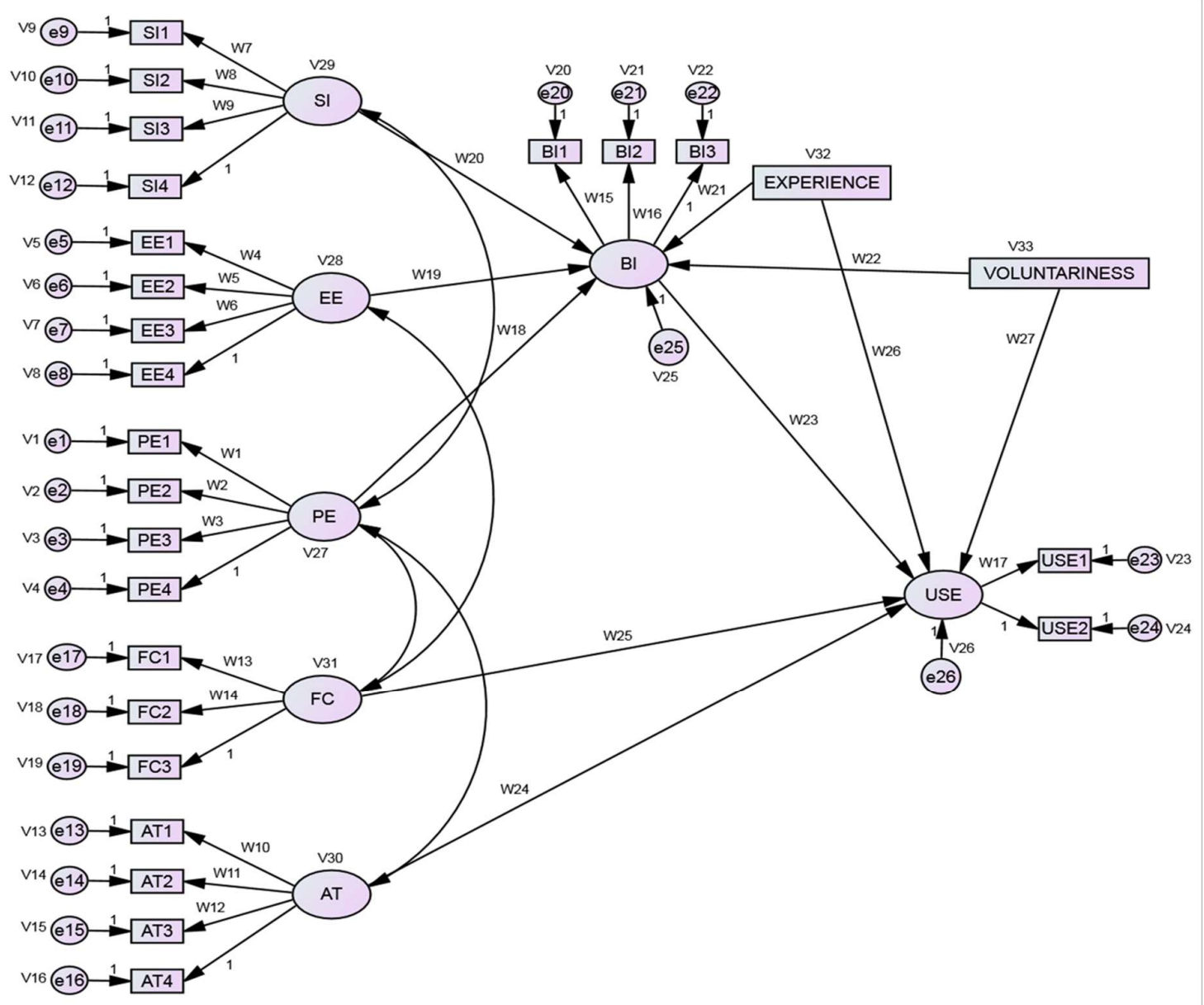

Figure 3: Structural model using SEM (see Abbreviations and Acronyms on page 3) 


\begin{tabular}{|c|ccccc|}
\hline Model & NPAR & CMIN & DF & P & $\mathrm{X}^{2} / \mathrm{DF}$ \\
\hline Default model & 64 & 763,017 & 287 & .000 & 2,659 \\
Saturated model & 351 & .000 & 0 & & \\
$\begin{array}{c}\text { Independence } \\
\text { model }\end{array}$ & 26 & $\begin{array}{c}2,432,4 \\
76\end{array}$ & 325 & .000 & 7,485 \\
\hline
\end{tabular}

Table 1: Chi-squared to degrees of freedom ratio 


\begin{tabular}{|c|c|c|c|c|}
\hline Model & $\mathrm{X}^{2} / \mathrm{DF}$ & RMSEA & GFI & CFI \\
\hline $\begin{array}{c}\text { Default } \\
\text { model }\end{array}$ & 2,659 & .148 & .585 & .774 \\
\hline
\end{tabular}

Table 2: Model fit measures 


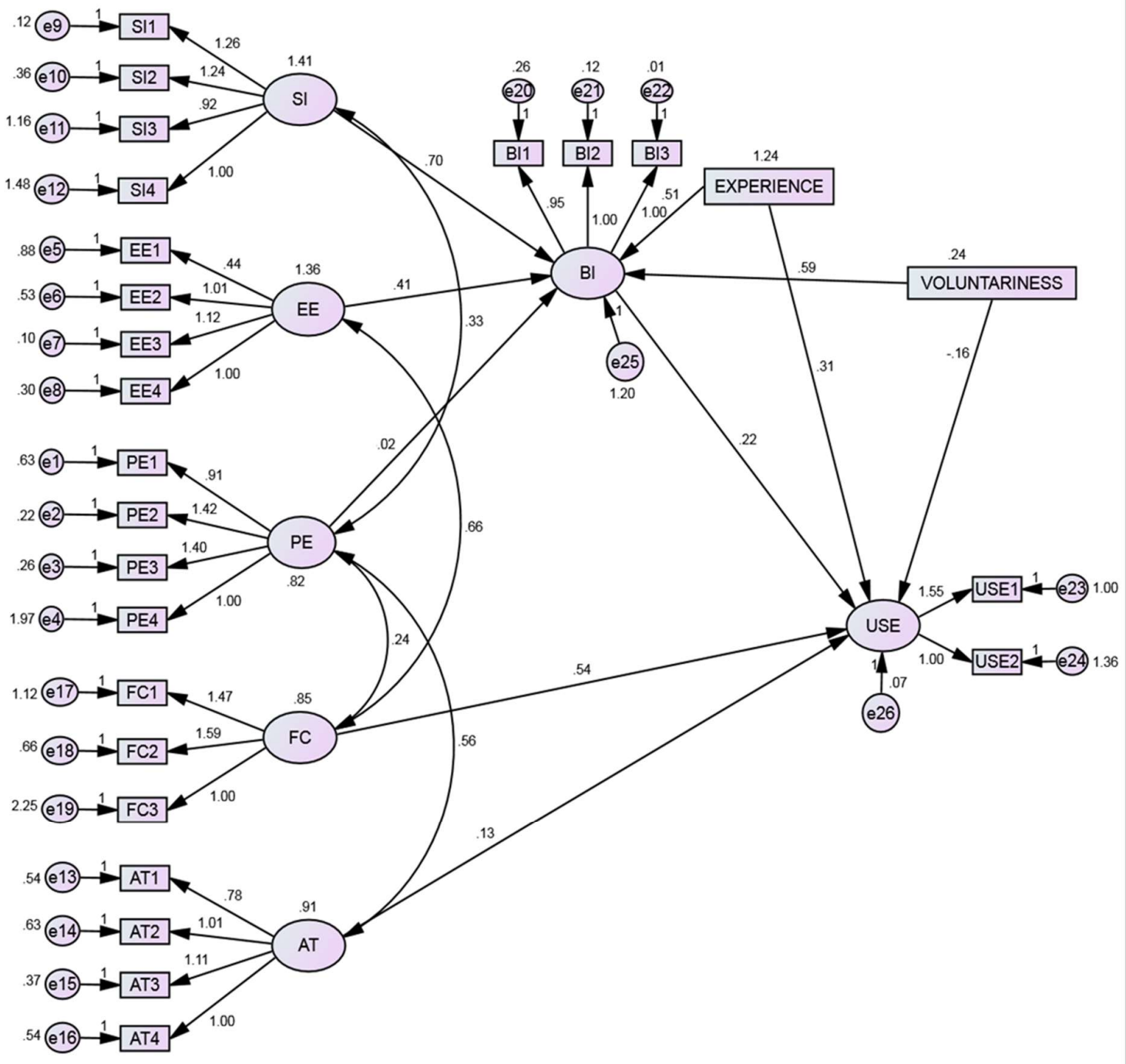

Figure 4: Path results for structural model (see Abbreviations and Acronyms on page 3) 


\begin{tabular}{|c|c|c|c|c|c|c|c|c|}
\hline Hypothesis & $\begin{array}{c}\text { Dependent } \\
\text { variable }\end{array}$ & Path & $\begin{array}{c}\text { Independent } \\
\text { variable }\end{array}$ & Estimate & S.E. & C.R. & P. & Label \\
\hline $\mathrm{H} 1$ & $\begin{array}{c}\text { Behavioural } \\
\text { Intention }\end{array}$ & $\leftarrow$ & $\begin{array}{c}\text { Performance } \\
\text { Expectancy }\end{array}$ & 0.015 & 0.154 & -.099 & .921 & W18 \\
\hline H1 & $\begin{array}{c}\text { Behavioural } \\
\text { Intention }\end{array}$ & $\leftarrow$ & $\begin{array}{l}\text { Performance } \\
\text { Expectancy }\end{array}$ & 0.218 & 0.171 & 1,276 & .202 & W18 \\
\hline $\mathrm{H} 2$ & $\begin{array}{c}\text { Behavioural } \\
\text { Intention }\end{array}$ & $\leftarrow$ & $\begin{array}{c}\text { Effort } \\
\text { Expectancy }\end{array}$ & 0.407 & 0.114 & 3.569 & 0 & W19 \\
\hline $\mathrm{H} 3$ & $\begin{array}{c}\text { Behavioural } \\
\text { Intention }\end{array}$ & $\leftarrow$ & $\begin{array}{c}\text { Social } \\
\text { Influence }\end{array}$ & 0.700 & 0.143 & 4.914 & 0 & W20 \\
\hline $\mathrm{H} 4$ & $\begin{array}{c}\text { User } \\
\text { Behaviour }\end{array}$ & $\leftarrow$ & Attitude & 0.127 & 0.086 & 1.477 & 0.14 & W24 \\
\hline H5 & $\begin{array}{c}\text { User } \\
\text { Behaviour }\end{array}$ & $\leftarrow$ & $\begin{array}{l}\text { Facilitating } \\
\text { Conditions }\end{array}$ & 0.543 & 0.161 & 3.371 & 0 & W25 \\
\hline H6 & $\begin{array}{c}\text { User } \\
\text { Behaviour }\end{array}$ & $\leftarrow$ & $\begin{array}{c}\text { Behavioural } \\
\text { Intention }\end{array}$ & 0.218 & 0.062 & 3.507 & 0 & W23 \\
\hline $\mathrm{H} 7$ & $\begin{array}{c}\text { Behavioural } \\
\text { Intention }\end{array}$ & $\leftarrow$ & Attitude & -.159 & .207 & -.766 & .444 & W24 \\
\hline
\end{tabular}

Table 3: Model Outcomes 


\begin{tabular}{|llll|}
\hline \multicolumn{1}{|c}{ Variable } & Path & \multicolumn{1}{c|}{ Variable } & Estimate \\
\hline Performance Expectancy & $\leftarrow$ & Facilitating Conditions & 0.284 \\
Performance Expectancy & $\leftarrow \rightarrow$ & Attitude & 0.648 \\
Performance Expectancy & $\leftarrow \rightarrow$ Social Influence & 0.306 \\
Effort Expectancy & $\leftarrow \rightarrow$ & Facilitating Conditions & 0.609 \\
\hline
\end{tabular}

Table 4: Correlations 


\begin{tabular}{|c|c|c|}
\hline No. & Study assumption & Verified result \\
\hline H1 & $\begin{array}{l}\text { Performance Expectancy will have a positive influence with the } \\
\text { individual's Behavioural Intention to use BIM. }\end{array}$ & Rejected \\
\hline $\mathbf{H 2}$ & $\begin{array}{l}\text { Effort Expectancy will have a positive influence with the individual's } \\
\text { Behavioural Intention to use BIM. }\end{array}$ & Accepted \\
\hline H3 & $\begin{array}{l}\text { Social Influence will have a positive influence with the individual's } \\
\text { Behavioural Intention to use BIM. }\end{array}$ & Accepted \\
\hline H4 & $\begin{array}{l}\text { Attitude will have a positive influence with the individual's User } \\
\text { Behaviour of BIM. }\end{array}$ & Accepted \\
\hline H5 & $\begin{array}{l}\text { Facilitating Conditions will have a positive influence with the } \\
\text { individual's User Behaviour of BIM. }\end{array}$ & Accepted \\
\hline H6 & $\begin{array}{l}\text { Behavioural Intention will have a positive influence with the } \\
\text { individual's User Behaviour of BIM. }\end{array}$ & Accepted \\
\hline H7 & $\begin{array}{l}\text { Attitude will have an influence with the individual's Behavioural } \\
\text { Intention. }\end{array}$ & Rejected \\
\hline
\end{tabular}

Table 5: Hypothesis testing results 


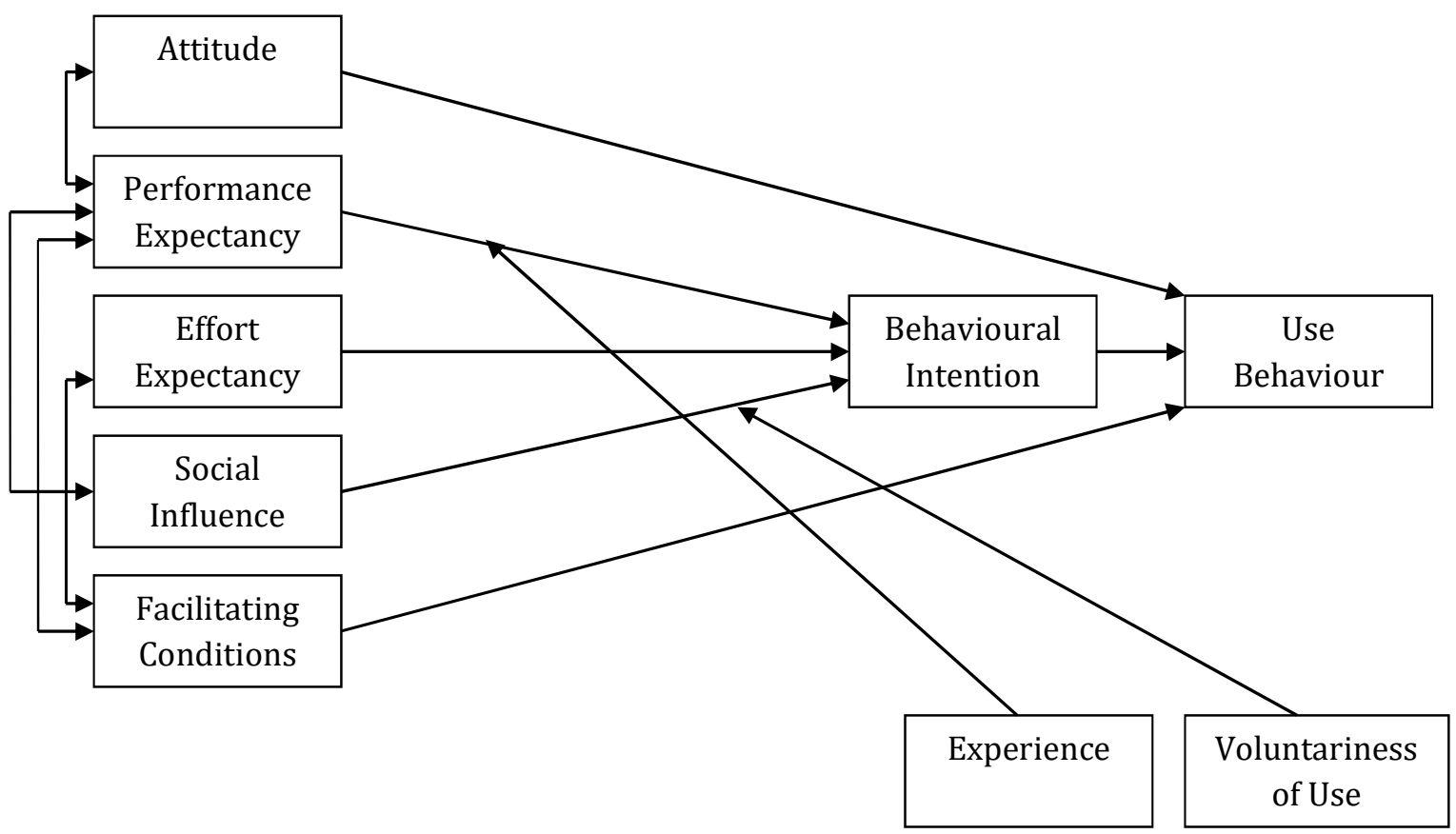

Figure 5: Revised Model Based on SEM Results 